\title{
Investigation of Serum Enzyme Activity of Nitric Oxide (NO), Arylesterase (ARE) and Paraoxanase (PON) in Renal Tumors
}

\author{
Tugba Gur ${ }^{1 *}$, Gulsen Enterili ${ }^{2}$, Necip Pirincci $^{3}$, Canan Demir ${ }^{1}$, Halit Demir ${ }^{2}$, Mehmet Kaba ${ }^{3}$, \\ Huseyin Eren ${ }^{3}$
}

\begin{abstract}
Objective: Reactive oxygen species (ROS) and antioxidant capacity have been implicated in the pathogenesis of various diseases, and cancers. Oxidative stress can cause tumor angiogenesis and may be carcinogenic. However, the relationship between antioxidant capacity and various cancers has been researched in several clinical trials.

Materials and Methods: In this study, we aimed to identify serum Nitric Oxide (NO), Arylesterase (ARE) and paraoxonase (PON) activities in patients with renal tumors. Serum ARE, PON and NO levels were measured by spectrophotometer.
\end{abstract}

Results: Increased activity of serum nitric oxide (NO) was determined in cancer group. Serum Arylesterase (ARE) were significantly lower in the patient group than the control group. Increased activity of Serum paraoxonase $(\mathrm{PON})$ were detected in the control group $(\mathrm{p}<0.05)$.

Conclusion: Our results indicates that Nitric oxide (NO), arylesterase (ARE) and paraoxonase (PON) activities may play an important role in the pathogenesis of renal cell cancer.

Keywords: Arylesterase, ARE, Nitric Oxide, NO, Serum paraoxonase, PON, Renal tumor

\section{Introduction}

Renal cell carcinoma accounts for $90-95 \%$ of all kidney malignancies (1). Advances in diagnostic imaging and early detection do not fully explain this trend Rates of renal cancers are higher among males and have been increasing more rapidly among African Americans than Whites. In the United States, approximately 30,800 new cases of renal cancer and 12,000 deaths from renal cancer are reported annually, making renal cancer the sixth largest cause of cancer deaths. The incidence of renal cell carcinoma has been increasing in the United States and worldwide by approximately $2-4 \%$ per year, for the last 20 years $(2,3)$. Established risk factors for renal cancer include smoking, use of phenacetin containing drugs, hypertension, obesity, and end-stage renal disease (ESRD)(4). Of the patients who present with local disease and are considered for surgery with curative intent, approximately one thirdwill go on to develop metastatic disease. Metastatic kidney cancer is resistant to all "standard" forms of radiation therapy, chemotherapy, and hormonal therapies used in the treatment of other kinds of carcinomas.
Reactive oxygen species (ROS) have been implicated in the pathogenesis of various diseases, including cancers (5). In previous studies, it has been demonstrated that ROS are directly suggested in oxidative damage of cellular macromolecules such as lipids, proteins, and nucleic acids in tissues (6). Moreover, oxidative stress can lead to tumor angiogenesis. It has also been reported that ROS can also augment tumor cell migration, increasing the risk of invasion and metastasis (7).

However, the relationship between antioxidant capacity and various cancers has been investigated in several clinical trials. Ray et al. reported increased lipid peroxidation (LPO) and production of reactive oxygen metabolites (ROMs) and decreased activities of superoxide dismutase (SOD) in breast cancer patients. Increased glutathione peroxidase (GSHPx) activity also was reported by the same researchers (8). Vitamin $\mathrm{E}$ is a supporter of antioxidant system, and a supplementation trial conducted in China showed a significant reduction in stomach cancer mortality (9). 
Oberley and Buettner (10) reported that the vast majority of the cancer cells have very low SOD activity, as compared with their normal cell counterparts. Gecit et al. reported that increased prolidase seems to be associated with increased nitric oxide (NO) levels and oxidative stress along with decreased antioxidant levels in bladder cancer (11).

In this study, we aimed to identify serum Nitric Oxide (NO), Arylesterase (ARE) and paraoxonase (PON) activities in patients with renal tumors

\section{Material and Methods}

A total of 32 male patients with renal cell cancer with a mean age of $55.32+2.9$ were included in the study. All of the patients have not smoked during their life, they were not addicted to alcohol, have not used the supportive antioxidant, and did not abuse any drug and have any metabolic disorders. There were no other major diseases or cancers in any of the patients except for the kidney tumor. All of the patients have been newly diagnosed, and their blood samples were received in the preoperative period. In all, 29 male patients who made up the control group (mean age $56.01+3.0)$ were randomly selected among the volunteers who did not have any known major disease and who did not use cigarettes, alcohol, drugs, and additional antioxidants. Patient and control groups had a similar socioeconomic status.

According to the results of radiological and postoperative histopathological evaluation, 24 (75\%) of our patients were in stage 1, $6(18.75 \%)$ of them were in stage 2 , and $2(6.25 \%)$ of them were in stage 4 of metastatic renal tumor.

The study protocol was carried out in accordance with the Helsinki Declaration as revised in 1989. All participants were informed about the study protocol and the written consent was taken from each one.

\section{Blood collection}

Following $12 \mathrm{~h}$ of fasting period, blood samples were taken in the morning, collected into empty tubes, and immediately kept on ice at $4{ }^{\circ} \mathrm{C}$. The serum was then isolated from the cells by centrifugation at $3000 \mathrm{rpm}$ for $10 \mathrm{~min}$. Serum samples for measurement of Nitric Oxide (NO), Arylesterase (ARE) and paraoxonase (PON) levels were kept at $20{ }^{\circ} \mathrm{C}$ until they were used.

\section{Nitric Oxide (NO) analysis}

NO levels in serum was determined using the Griess reaction (12). Griess solution X: 0.1 g NED (N-1naphthyl)-ethylenediamine dihydrochloride) was weighed and dissolved in $100 \mathrm{ml}$ water. Again, Y Griess solution: $1 \mathrm{~g}$ sulphanilamide in $100 \mathrm{ml}$ of orthophosphoric acid (5\%) was dissolved in a solution.
The 100 mico liter sample was taken and each tube was placed in a $0.1 \mathrm{ml}$ Griess solution $\mathrm{X}$ and $0.1 \mathrm{ml}$ Griess solution $\mathrm{Y}$ equal to tubes placed in and stirred, then 15 minutes at room temperature was allowed to stand and each sample at $540 \mathrm{~nm}$ absorbance values were read.

\section{Arylesterase (ARE) analysis}

Arylesterase activity in 2004 and 2005, developed by Erel was determined with a kit $(13,14) .10 \mu \mathrm{ml}$ onto $990 \mathrm{ml}$ diluent solution was added 10/100 ratio dilutions were performed this diluted from the $3 \mu \mathrm{ml}$ enrolled over $260 \mu \mathrm{ml}$ pure water (Reagent 1) was added, then $10 \mu \mathrm{ml}$ Reagent 2 was added, then vortexed and at $548 \mathrm{~nm}$ enzyme activity was measured.

Measurements are taken more spectrokuvet A1 80 $\mu \mathrm{ml}$ Reagent 3 was added and again after waiting 4 minutes at $548 \mathrm{~nm}$ was measured and the measurements of activity is defined as A2. For activity measurement $($ enzyme unit $)=(\Delta \mathrm{A} 2-\Delta \mathrm{A} 1) \times 1316$.

\section{Paraoxanase (PON) analysis}

Paraoxonase activity in 2004 and 2005, developed by Erel was determined with a kit $(13,14)$. The two tubes are each $500 \mu \mathrm{ml}$ reagent 1 (buffer solution) was added and on $25 \mu \mathrm{ml}$ sample (serum) was added and stirred then $25 \mu \mathrm{ml}$ reagent 2 (substrate solution) was added $30 \mathrm{sec}$ and $150 \mathrm{sec}$ after the absorbance measurement at $412 \mathrm{~nm}$ was read. Activity measurement $(\mathrm{U} / \mathrm{L})=((\Delta 150 \mathrm{sn}-\Delta 30 \mathrm{sn}) / 2) \times 1202.84$

\section{Statistical analysis}

Descriptive statistics for the studied traits were expressed (reported) as mean, standard deviation, minimum, andİstatistiksel yorum maximum values. Student's $t$ test was used for comparison of groups. In the study, 5\% level was taken into account to the statistically significant differences between groups, and SPSS Statistical package program (ver. 13) was used for the all statistical computations.

\section{Results}

The demographic and clinical data of bladder cancer and control groups are shown in Table 1. There were no statistically significant differences between renal cancer patients and controls with respect to age and body mass index (BMI) (all ps >0.05; Table 1).

Serum NO level was significantly higher in renal cancer than in controls (all ps <0.05); while ARE and PON levels were significantly lower $(p<0.05$; Table 2). No correlation was observed between tumor staging and serum NO, ARE and PON levels (ps > $0.05)$. 
Table 1: Demographic characteristics of the two groups in this study

\begin{tabular}{lcc} 
Parameters & $\begin{array}{c}\text { Control } \\
(\mathbf{n = 3 2})\end{array}$ & $\begin{array}{c}\text { Patients } \\
(\mathbf{n = 2 9})\end{array}$ \\
\hline Age, year & $55.32 \pm 2.9$ & $56.01 \pm 3.0$ \\
Body mass index, $\mathbf{k g} / \mathbf{m}^{2}$ & $21.56 \pm 1.86$ & $21.33 \pm 1.29$ \\
\hline
\end{tabular}

Table 2: Descriptive statistics and comparison results according to the groups for specifications.

\begin{tabular}{|c|c|c|c|}
\hline & $\begin{array}{c}\text { Patients }(\mathbf{n}=\mathbf{3 2}) \\
(\mathrm{X} \pm \mathrm{Sx})\end{array}$ & $\begin{array}{c}\text { Control }(\mathbf{n}=\mathbf{2 9}) \\
(\mathrm{X} \pm \mathrm{Sx})\end{array}$ & $p$ \\
\hline NO $(\mu \mathrm{mol} / \mathrm{L})$ & $8.397 \pm 2.0981$ & $1.192 \pm 0.1474$ & $<0.001$ \\
\hline ARE (U/mL) & $17.518 \pm 3.5288$ & $42.170 \pm 6.8991$ & $<0.001$ \\
\hline PON (U/mL) & $57.570 \pm 7.2911$ & $94.423 \pm 4.7110$ & $<0.001$ \\
\hline
\end{tabular}

\section{Discussion}

Biological and biochemical systems (CAT), peroxidase (POD), glutathione reductase (GSSG-Rx) and superoxide dismutase (SOD) are enzymes having antioxidant activity. Antioxidant defense system, cell free radical or other reactive molecules protects

against oxidative damage. Therefore, this defense system, CAT, POD, PON, ARE, GSSG-Rx and antioxidant enzymes such as SOD is of great importance. The harmful effects of free radicals in cells are controlled by antioxidant defense systems (15).

Although some possible mechanisms through which oxidative stress exerts a regulatory role in tumor growth and progression including genomic instability (16), oncogene activation (17), and angiogenesis (18) are known, several important questions remain unanswered. It is not clearly known whether oxidative stres and tumor result from an increased oxidant production or from a failure of antioxidant systems (19). Although important changes in cellular redox homeostasis during tumor growth have been documented in experimental models, such variations have not been shown in humans. Most of the difficulties encountered in these studies are related to the complexity of the biochemical pathways that regulate the cellular redox balance $(20,21)$. A wide variety of oxidizing molecules such as ROS and/or depleting agents can change the glutathione redox state, which is normally maintained by the activity of GSH depleting (GSH-Px) and replenishing enzymes (glutathione reductase). The importance of GSH and related enzymes and their variation in tumors has been poorly studied $(17,21)$.

Abnormal cell proliferation in the serum cancerous patient is the cause of lipid peroxidation (LP) increase. The increase in LP in cancer may also be owing to the poor antioxidant system as observed in the previous studies (22).
It has been claimed that MDA acts as a tumor promoter and cocarcinogenic agent on account of its high cytotoxicity and inhibitory action on protective enzymes $(23,24)$. The data reported in the literature on MDA levels in different human cancer types are controversial. On the other hand, MDA, the major aldehyde end product of LP of membrane polyunsaturated fatty acids by free radicals, is an indicator of oxidative stress (25). In the present study, we found a significantly increased serum MDA levels in patients with renal cancer than in control subjects.

The data reported in the literature on oxidant, antioxidant molecule, and enzymes in different human cancer types are controversial. For instance, in a study the activities of SOD and GSH-Px enzymes were found lower in malignant liver tissues during rat hepatocarcinogenesis (26). In another one, Corrocher et al. (27) established that in human hepatoma the enzymatic antioxidant system was severely impaired owing to lowered GSH-Px activities. Nakada et al. (28) measured SOD activities in renal cell carcinoma and nontumorous renal tissues. They found no meaningful differences between the activities of the cancerous and noncancerous parts and suggested that it was unlikely for SOD to play a part in the development of renal cell carcinoma since SOD activities in tumor tissue were similar to those in nontumorous renal tissues. Ray et al. (8) observed a significant increase in SOD and GSH-Px activities in patients with gastric cancer compare to the control group. Ozturk et al. (29) observed a significant increase in xanthine oxidase (XO) activity in patients with cancerous human colorectal tissues compared to control group. The increased GSH-Px activities and GSH levels are reported in patients with leukemia (30,31). In our study group, serum ARE was significantly lower than the control group $(\mathrm{p}<0.001)$. 


\section{Conclusions}

According to the results of our study of patients with renal cell carcinoma was found a decrease in the antioxidant defense system. Oxidant/antioxidant balance of damage in the development kidney cancer might be considered a risk factor. This is relevant for the formation of a consensus randomized prospective studies are needed.

Conflict of Interest: The authors declare no potential conflicts of interest with respect to the research, authorship, and/or publication of this article.

Acknowledgement: There is no any financial support and conflict for 'Investigation of Serum Enzyme Activity of Nitric Oxide (NO), Arylesterase (ARE) and Paraoxanase (PON) in Renal Tumors" entitled article. Author Contributions: TG; Design of study, Writing of Article GE, NP, CD, HD, MK, HE; Patient selection, Blood sample analysis HE; Editing of Article

Ethical issues: All Authors declare that Originality of research/article etc... and ethical approval of research, and responsibilities of research against local ethics commission are under the Authors responsibilities. The study was conducted due to defined rules by the Local Ethics Commission guidelines and audits.

\section{References}

1. Curti BD, Renal cell carcinoma. JAMA,. 292, 97-100 (2004).

2. Chow WH, Devesa SS, and Warren JL et al., JAMA 281,1628-31(1999).

3. Dhote R, Pellicer-Coeuret M, Thiounn N, et al., BJU Int.86: 20-7 (2000).

4. McLaughlin JK, Blot WJ, Devesa SS et al., Renal cancer. In: Schottenfeld D and Fraumeni JF (eds) Cancer Epidemiology and Prevention. New York, NY: Oxford University Press, pp. 1142-55 (1996).

5. Templar J, Kon SP, Milligan TP, et al., Nephrology Dialysis Transplantation 14, 946-51(1999).

6. Batcioglu K, Mehmet N, Ozturk IC, et al., Cancer Invest 24, 18-21(2006).
7. Nishikawa M, Cancer Lett, 266, 53-9 (2008).

8. Ray G, Batra S, Shukla NK et al., Breast Cancer Res Treat.59:163-70 (2000).

9. Wang GQ, Dawsey SM, and Li Y, Cancer Epidemiology, Biomarkers and Prevention, 3,161-66 (1994).

10. Oberley LW, and Buettner GR, Cancer Research 39: 11419 (1979).

11. Gecit I, Aslan M, Gunes M, et al., J Cancer Res, Clin, Oncol., 138: 739-43 (2012).

12. Cortas NK, and Wakid NW. Clin. Chem., 36, 1440-1443 (1990).

13. Erel O. Clin. Biochem, 37, 112-229 (2004).

14. Erel O, Clin. Biochem, 38, 1103-1111 (2005).

15. Gülçin I, Oktay M, Küfrevioğlu, ÖI, and Aslan A, Journal of Ethnopharmacology, 79 (3), 325-329 (2002).

16. Jaruga P, Zastawny TH, Skokowski J, et al., FEBS Lett. 341(1),59-64 (1994).

17. Sun Y, and Oberley LW, Free Radical Free Radic, Biol, Med. 21: 335-48 (1996).

18. Blackburn RV, Spitz DR, Liu X, et al., Free Radic Biol, Med, 26, 419-30 (1999). 9) Toyokuni S, Okamoto K, Yodoi J, et al., FEBS Lett.16, 3581-3 (1995).

19. Meyer TE, Liang HQ, Buckley AR, et al., International Journal of Cancer 3: 55-63 (1998).

20. Mantovani G, MaccioA, Madeddu C, et al., International Journal of Cancer 98: 84-91 (2002).

21. Szatrowski TP, and Nathan CF, Cancer Res. 51, 794-8 (1991)

22. Marnett LJ, Mutat Res 424, 83-95 (1999).

23. Seven A, Civelek S, Inci E, et al., Clinical Biochemistry, 32, 369-73 (1999).

24. Marnett LJ, Carcinogenesis. 21, 361-370 (2000).

25. Vo TKO, Druez C, Delzenne N, et al., Carcinogenesis. 9(11), 2009-2013 (1988).

26. Corrocher R, Casaril M, Bellisola G, et al., Cancer, 58(8), 1658-62 (1986).

27. Nakada T, Akiya T, Koike H et al., Eur Urol, 14(1), 50-5 (1988)

28. Ozturk HS, Karaayvaz M, Kacmaz M, et al., Cancer Biochemistry Biophysics, 16, 157-168 (1998).

Ferraris AM, Rolfo M, Mangerini R, et al., Am J Hematol., 47, 237-278 (1994).

30. Farber CM, Kanganis DN, Liebes LF, et al., Br J Haematol 72, 32-35 (1989). 